\title{
Cybercafes and their Potential as Community Development Tools in India
}

\author{
Anikar M. Haseloff \\ Universität Augsburg < anik.haseloff@web.de $>$
}

\begin{abstract}
Using public Internet facilities in order to access information and communication technologies (ICT) is the main model of use after the more common models of home use (individual ownership) and access at work or at school/university. Especially in developing countries, public and shared facilities help to create desperately needed access and are a main strategy in several Internet access programs. In the context of public access, cybercafes play an important role as the most common Internet access model, especially in the urban areas of India. It is often argued that cybercafes could help bridge the digital divide, as they provide Internet access to people who cannot afford to have Internet connections at their homes or who need help in order to make use of ICT. The following article will take this assumption as a starting point and will present findings from empirical research on cybercafes in urban India. The research was conducted in order to explore the problems and potential of cybercafes as development tools for different urban communities. In order to examine these relationships, the reach of cybercafes, the users of cybercafes and the usage patterns have been examined. This study is part of a doctoral thesis and the following article presents some of the findings. The article has to be seen as a preliminary report on ongoing research, and it presents some of the data collected to date in order to help build understanding concerning this complex access model and its importance for urban India.
\end{abstract}

\section{Introduction}

The Internet is dramatically changing the way people live, work, communicate, recreate and participate in public life all over the world. But the growth and the penetration of the Internet is far from being distributed equally around the globe. Whereas in developed countries the Internet today reaches substantial proportions of the population, e.g. in Germany $(56.2 \%)$ or in the United States $(68.8 \%)$, the situation is different in developing countries. In India for example, only 2.9 percent of households had Internet access in early 2005. This is almost twice the average for African countries ( $1.5 \%$ Internet penetration), but still much lower than the world average (13.9\% penetration) and India is still far behind Europe with $35.5 \%$ (all statistics from: http://www.internetworldstats.com/).

The low rates of Internet access in developing countries like India are often traced back to low rates of personal computer ownership and the high cost of hardware. Another barrier is the low income level, which makes the Internet an expensive tool in developing countries. Beside these economic factors, there are a variety of cognitive barriers like low literacy rates, lack of English language skills or lack of e-literacy skills to effectively use these new technologies (Warschauer, 2003).

As a result of the low penetration of ICT tools in Indian households, a substantial proportion of the Indian population has to rely on other modes of access to the Internet, mainly by using public Internet access points. In this, there are a wide variety of different public models, ranging from public libraries offering Internet access, to rural village information kiosks and telecenters, to modern urban cybercafes. The various models offering public Internet access differ significantly between urban and rural areas as well as between developed and developing countries. Whereas in rural areas development oriented projects 
are the most common and mostly the only public access model, cybercafes in urban areas are the prevalent model of public Internet access beside other public facilities like libraries, schools or municipal projects.

While in their initial stage a mostly urban phenomena, cybercafes over the years have mushroomed throughout India, and today can even be found in small towns and some of the bigger villages. They seem to serve a crucial portion of Indian society as access points for the use of computers and the Internet, as can be seen when examining the size of this sector. As there is a lack of common definitions, regulations for registration, and authoritative measurement, the exact number of cybercafes in India can only be roughly estimated. There exist several such figures, but they have to be seen as estimates rather than exact numbers. In 2001 the Indian Market Research Bureau (IMRB) estimated around 12,000 cybercafes in India (Achar, 2001). Since then the number appears to have grown steadily all over the country, and Caslon Analytics (2004, p. 4) estimates the number of cybercafes for all of India as approximately 50,000 in 2004. The same figure is given by Pasricha (2004). These estimates show that cybercafes are slowly becoming part of contemporary city architecture in India and may serve a large proportion of the Indian population as access points to the Internet.

Despite the fact that the number of cybercafes in the urban areas of India (as well as in most parts of the rest of the world) has increased significantly, cybercafes are mostly ignored in scientific research and political programs, which seem to prefer to concentrate on other public access services in libraries, community access centers, village information centers, schools or universities. Little attention has been paid so far to this obviously successful market-driven access model and there is a lack of empirical data, as well as a lack of user surveys measuring the usage patterns of these enterprises. Therefore the users, the usage patterns and the relevance of cybercafes for particular social groups in India remain almost unknown.

\section{Definition of cybercafes}

Cybercafes in this article are understood as "for-profit facilities, open to the general public to access the Internet, other network facilities and/or a variety of information technology tools on a temporary contract basis (pay per use) without the necessity for the users to own hardware or software themselves."

This simple definition segregates cybercafes from organizational, governmental or institutionally implemented rural Internet projects with primarily developmental attitudes and goals. One of the main differences between urban cybercafes and organizationally implemented rural Internet projects may be seen in the management goals of the different models. Whereas rural Internet projects often target low-income groups and are able to offer their services free or with significant subsidizes, cybercafes are in a stiff competition and usually target the better-off parts of the society.

The above definition also segregates cybercafes from other common public Internet access facilities in urban areas such as, for example, public libraries that offer Internet access to their users or community access centers that offer Internet access to specific target groups. Cybercafes usually are open to everybody who can afford to pay the service fees and there are usually no restrictions with respect to age, gender, ethnicity, religion or income. Use is normally charged on a minutes/hours basis without the need of having a contract or a registered membership.

Cybercafes today appear in a variety of different models. They range from the original small-scale entrepreneur model, where a small number of computers using a slow dial-up connection is set up in a convenient atmosphere; to traditional cafés which extend their existing services by offering Internet access; to franchised ultra-modern Internet pools with a very large number of computers and broadband connections offering the same standardized services in different cities. More detailed classifications of cybercafes can be found in the works of Lachmayr (2003), Liff and Steward (2003) and Laegran and Stewart (2003), where cybercafes are classified according to the atmosphere, the function, the management type and their users.

In this article cybercafes are operationally defined as commercial venues that offer Internet access to the general public on a pay-per-use basis. They don't receive any kind of external funding and are not implemented within development programs or political initiatives. They have become almost ubiquitous in the urban areas of India and are now moving towards rural areas. In the rural areas of India however, development-oriented or funded projects are the prevalent models of public access and thus the findings of this study should be seen as being strictly limited to referring only to urban centers. 


\section{The emergence of cybercafes}

Stewart (2000, p. 322) dates the emergence of the first cybercafes to the early 1990s in the USA. According to those interviewed in this study, they appeared in the Indian scene in the mid-1990s, mainly in metropolitan areas like Mumbai, Delhi or Bangalore. Liff and Steward trace the evolution of this public access model in western countries back to the emergence of the World Wide Web, the invention of the graphical and easy-to-understand web browsesr like Mosaic (1993) or Netscape (1994) and the invention of free web-based email (Liff and Steward, 2003, p. 323).

There has been a massive boom worldwide of cybercafes in the late 1990s, with the biggest cybercafe (800 computers) in the world opening in New York in 2000 (Lachmayr, 2003). A similar development has been observed for India, where Achar identifies the years from 1998 through 2000 as the massive boom time for cybercafes. After growing until 2003/2004, the scene today is witnessing a small downturn, due to stiff competition and growing home access in the upper and middle classes. This can be seen, for example, in the dramatic reduction of access rates for customers, which have come down from around 70 Rupees (1.20 Euro) an hour in 1997 to as little as 10 Rupees (0.17 Euro) today, which makes it more difficult for cybercafes to create sustainable revenues (Achar, 2001). Despite these market consolidations, the number of cybercafes is extraordinarily high in India, based on the previously quoted estimates of up to 50,000 cybercafes.

Today cybercafes are the most visible and perhaps most important model of public Internet access in urban areas of India. Taking the recent explosive development of cybercafes as a starting point, this article will examine the potential that cybercafes could have in bridging the digital divide, and then describe the users of cybercafes in order to examine the reach of this model in urban India.

\section{Cybercafes and the digital divide}

The unequal access within and among countries to ICTs is often called the digital divide. This catchy label points to a multidimensional phenomenon and describes disparities in access to ICT along various axes and at various levels. Whereas the existence of a digital divide in one or the other form is clearly accepted amongst scholars, the dimensions, the dynamics and the relevance of this phenomenon are still being widely discussed (Compaine, 2001; Mossberger, Tolbert, and Stansbury, 2003; Norris, 2001; Warschauer, 2003).

It is a common mistake to limit the existence and importance of the digital divide only to its access and infrastructure aspects. Although access is a prerequisite for the use of new ICTs, making effective use and deriving benefits from ICTs requires strategies which go beyond providing simple access and include the development of the needed skills, relevant content and applications as well as a technology supportive environment (Gurstein, 2003).

Cybercafes in this context, it should be noted, originated as a purely access-driven solution to provide shared and therefore consequently cheaper access to people who temporarily or generally lack access.

Disparities in access can be observed in every country, and Internet access is far from reaching the entire population, even in countries with high rates of Internet access (Warschauer, 2003, p. 75):

(...) it will take decades before nearly every household in developed countries has Internet access, and much longer than that before universal home Internet service is reached in developing countries. It is thus necessary to enhance the provision of Internet connectivity through the establishment of public access sites.

Therefore, cybercafes as the most common form of public Internet access in urban areas can be seen as a helpful institution to overcome access divides in emerging countries. But cybercafes in this discussion should not be seen as limited to the access level of the digital divide. Cybercafes are interesting because of two mechanisms. On the one hand, cybercafes offer a low-cost alternative to the otherwise expensive model of in home-ownership and access in developing countries, and thus lower the multiple financial barriers (investment in hardware and software, monthly cost, expenses for updates or security). On the other hand, cybercafes can function as a center for support, education and learning about new tools and 
therefore could help people overcome skill deficits which would normally exclude them from access to new technologies.

The main mechanisms which can be identified in the context of cybercafes and the digital divide are:

- Access Level: Cybercafes provide access to people who cannot afford to have computers and Internet connections at home. This is especially important and highly visible in urban areas of developing countries like India.

- Access Level: Cybercafes offer by far the largest number of computers accessible to the public compared to the other models like libraries, school or universities.

- Technology Level: They may provide better equipment or faster connections to enable different and more advanced use.

- Skill Level: Cybercafes can offer formal training and beginner courses for people who lack the skills to use computers and the Internet. Besides this, help and support can be realized informally from the staff or other users if problems occur.

- Social Exclusion Level: Cybercafes could address special target groups, which are normally underrepresented in the Internet user statistics, e.g., elderly people or people with low income.

- Socialization and Mobilization Level: Cybercafes may also have an important function in socializing the new tools and technologies by displaying them and their use to the public and, therefore, perhaps motivating further use.

These theoretical assumptions are challenged in the most developed countries by the explosion in the number of in-home users (Caslon Analytics, 2004, p. 5). Cybercafes can be seen in the context of the most developed countries as just transitory necessities, which will diminish with steadily growing in-home access. But even though the cybercafe isn't a necessity in the most developed countries, it is a special and dedicated use space for some communities, and therefore is not necessarily a transitory phenomenon (Stewart, 2000). As well, the situation may be different in developing countries like India: “(...) computers will remain out of reach for most of India's one billion people for years to come, so cyber cafes will continue to be the vehicle for taking the Internet to the masses" (Pasricha, 2004).

But do cybercafes really take the Internet to the masses? Or do they just serve an urban elite? There is evidence that in western countries cybercafes mostly serve people who already have access elsewhere, as a survey done in Vienna by Lachmayr shows. He conducted a study of 255 users from 13 different cybercafes in Vienna in order to find out if cybercafes help to bridge the digital divide, but the findings clearly don't support this hypothesis. The users of cybercafes in Vienna have been mostly young (average age 23), male (61 percent male), students (30 percent) or self-employed (27 percent). Lachmayr concludes that the users of cybercafes are mostly people who already have a decent knowledge of new technologies and who in most cases have access elsewhere. In fact,cybercafes could even be seen as widening the divide, as the research suggests that cybercafes are only offering an additional resource to people who already use the new technologies, while leaving behind those without any other option (Lachmayr, 2003).

As mentioned above, the situation may be a little different in India. On the one hand, home use of the Internet will remain out of reach for substantial proportions of the society in India. On the other hand, cybercafes are found in much higher numbers in the Indian cities than, for example, in Vienna, which could imply a higher demand for this access model in India. As there is very little empirical research on cybercafes in India, exploratory baseline data were collected in different Indian cities in early 2004 and early 2005. This research was designed to answer the following questions:

- Who is using cybercafes in the urban areas of India?

- What are the reasons people use cybercafes?

- Do disadvantaged groups such as the elderly, low-income groups or those with low education levels use cybercafes, or are cybercafes just an additional access point for people who already have access elsewhere?

- Does the relevance of using cybercafes differ for various groups?

A brief description of the methods used and a discussion of some of the findings are given below.

\section{An exploratory survey of cybercafes}


In order to examine the importance of cybercafes, a street survey was conducted in Bangalore in February 2005. Bangalore was chosen because it is known as the IT capital and hosts the most cybercafes in India (Achar, 2001). The questionnaire was designed to collect socioeconomic data form respondents (age, gender, income, education and occupation), their language abilities, their knowledge of the Internet, their place of Internet access, reasons for using or not using the Internet and future plans for Internet ownership or usage. The interviewers were given quotas and they were advised to work in different areas of the town, using a random walk method covering the entire city.

To classify respondents, the socio-economic classifications (SECs) developed by the (Indian) National Readership Survey were employed. The SEC groups urban Indian households using two factors: education and the occupational status of the chief wage earner of the family. There are five main SECs, ranging from A (highest group) to E (lowest). In the following survey, SEC A and SEC A1 are considered as upper class, SEC B is considered upper middle-class, SEC C is referred to as middle-class and SEC D and SEC E are considered lower class.

For the sample, the quotas for the SECs was not set according to the population statistics of Bangalore, as Internet use in the lowest SEC groups D and E is assumed to be almost nonexistent. In order to get higher samples of Internet users, SEC groups E and D have been heavily under-represented and SEC groups $\mathrm{A}$ and $\mathrm{B}$ have been over-represented in the quotas for the interviewers. Table 1 gives an overview of the SEC classes in Bangalore and the SEC classes in the surveyed sample:

Table 1: SEC Classes street survey

\begin{tabular}{|l|l|l|}
\hline Socioeconomic Class (SEC) & Percentage Bangalore & Percentage Survey \\
\hline \hline & & \\
\hline A1 & 6.4 & 18.3 \\
\hline A2 & 5.1 & 17.3 \\
\hline B & 15 & 28.9 \\
\hline C & 24.5 & 27.8 \\
\hline D & 22.9 & 4.5 \\
\hline E & 26 & 3.1 \\
\hline
\end{tabular}

$\mathrm{N}=1500$

Data Bangalore from Businessworld 2005 p. 72

The findings therefore have an exploratory character and the data do not claim to be representative for India (or Bangalore) as a whole, but it does give an interesting picture of the target group (Internet users) at the time of the survey.

\section{Findings}

\section{Internet usage}

In the surveyed sample $(\mathrm{N}=1496), 16.5$ percent of the respondents used the Internet. The Internet usage rate for Bangalore is 8.8 percent, according to the 2005 Marketing Whitebook (Businessworld, 2005, p.181), but as explained above, the higher usage rate came from the different weighting of the SEC groups in this survey.

Internet use varied strongly among the different groups. SEC D and SEC E show no Internet usage at all, as assumed before, whereas SEC A1 has a relatively high Internet usage level of 36.1 percent (matching the European average). Table 2 gives a short overview of the Internet usage in the different SEC groups:

Table 2: SEC group and Internet usage 


\begin{tabular}{|l|l|}
\hline SEC & Internet Usage \\
\hline \hline A1 & \\
\hline A2 & 36.1 \\
\hline B & 23.3 \\
\hline C & 12.9 \\
\hline D & 7.7 \\
\hline E & 0 \\
\hline N $=1496$ & 0 \\
\hline
\end{tabular}

Internet usage in percent of respondents

As can be clearly seen, Internet usage strongly declines in the lower SEC groups. If examined using the variable of income, Internet usage shows the same pattern (Table 3).

Table 3: Income and Internet usage

\begin{tabular}{|l|l|}
\hline Income & Internet Use \\
\hline \hline No income & \\
\hline Below 2500 & 0 \\
\hline $2600-5000$ & 0 \\
\hline $5100-10000$ & 5.1 \\
\hline $10100-25000$ & 16.3 \\
\hline $25100-50000$ & 30.2 \\
\hline Above 50000 & 42.4 \\
\hline
\end{tabular}

$\mathrm{N}=1496$

Internet use in percentage of respondents

Tables 2 and 3 show clearly that Internet usage is strongly associated with income and SEC. These findings are not surprising, as Internet use in developing countries is known to be highly unequal in distribution and, as in the early days of the Internet in western countries, it is used mostly by the elite.

\section{Language}

Another important variable that could influence the usage of the Internet is language, more specifically: the ability to speak English. An interesting case study in Slovenia observes a strong relationship between the ability to speak English and the use of the Internet. Internet use was as high as 75 percent in the group of fluent English speaking respondents, compared to just 1 percent of the respondents without English language skills (Vehovar, Batagelj and Lozar, 1999 p. 4). The same pattern was observed in this survey where the ability to speak English was determined as fluent, can understand to some extent and doesn 't speak. Table 4 shows the results.

Table 4: Internet usage and English language skills

\begin{tabular}{|l|l|l|l|}
\hline English Language skills & Fluent Speaker & Understand to some extent & Doesn't speak \\
\hline Internet Usage & 34.4 & 3.7 & 0.4 \\
\hline
\end{tabular}

$\mathrm{N}=1460$

Internet usage in percentage of respondents

As the table shows, Internet usage correlates strongly with the ability to speak English. The percentage of users in the group with very good English skills is almost as high as in SEC A1 (Table 2). Of course, the ability to speak English depends strongly on education and socio-economic level. For example, from the respondents in SEC A1, 76.6 percent were fluent in the English language, whereas in SEC C just 27.5 
percent were fluent English speakers and in SEC E nobody could speak fluent English. But the relation between the ability to speak English and usage of the Internet can also be observed by just examining SEC A1: 46.7 percent of the respondents with very good English skills were using the Internet, whereas just 2.5 percent of the respondents with only basic skills use the Internet and none of the non-speakers did. The same pattern can be observed when controlling for income. In the highest income groups, Internet usage was 46.7 percent if the respondent had fluent English language skills and only 1.5 percent if the respondent had only basic skills.

It can be argued that in order to make use of the Internet, one needs to understand English because of the prevalence of content in English on the web, but actually, nowadays there is considerable content available in a variety of Indian languages, so the lack of content can not explain this pattern. The relation between language and Internet use needs to be investigated more closely by future studies, as there could be some interesting mechanisms at work which are limited to the relation between content and language.

\section{Place of access}

If the respondent was using the Internet, s/he was asked about place(s) of access. Respondents could choose among home, work, friend, school/university and cybercafe, and it was possible to choose more than one access place. Interestingly, cybercafes are used by 67.3 percent of the respondents, which closely matches the two-thirds ratio noted by Pasricha (2004).

According to the survey, cybercafes are the most used access place, followed by work (44.1 percent) and school/college/university (26.3 percent). Home access, which is the prevalent access model in western countries, is important only for a small proportion ( 24.1 percent) of the Internet users. Table 5 gives an overview of the importance of each access point for the different SEC groups.

Table 5: SECs and access place

\begin{tabular}{|l|l|l|l|l|l|}
\hline & SEC A1 & SEC A2 & SEC B & SEC C & Total \\
\hline Home & 37.8 & 22 & 12.5 & 6.3 & 24.1 \\
\hline Work & 59.2 & 47.5 & 30.4 & 15.6 & 44.1 \\
\hline Friend & 15.9 & 13.6 & 19.6 & 15.6 & 15.9 \\
\hline Schoo1/University & 26.9 & 25.4 & 35.7 & 28.1 & 26.3 \\
\hline Cybercafe & 67.3 & 61.0 & 71.4 & 75.0 & 67.3 \\
\hline
\end{tabular}

$\mathrm{N}=244$

Figures in percentage of respondents

multiple answers possible

As this table shows, cybercafes are heavily used among all SEC groups, with the percentage of respondents using cybercafes being higher in SEC groups B and C. Access place home is almost double that of the next higher SEC group. A somewhat similar pattern can be found with work. The other two access options friends and school/university are, compared to cybercafes, home and work, relatively stable throughout the SEC groups. Table 5 also shows that the SEC group A1 generally uses more access points than the SEC group C (210 percent points compared to 140).

Respondents were also asked to identify the main place they would access the Internet. Table 5 shows that cybercafes are the main access point for the middle-class (SEC C) and even the upper middle-class (SEC B), whereas for the upper-class (SEC A1 and A2) the access place work is most important.

Table 5: Main Internet Access Place

\begin{tabular}{|l|l|l|l|l|l|}
\hline & SEC A1 & SEC A2 & SEC B & SEC C & Total \\
\hline Access Place & & & & & \\
\hline Home & 15.3 & 6.7 & 9.3 & 3.1 & 10.2 \\
\hline Work & 46.9 & 38.3 & 24.1 & 15.6 & 35.7 \\
\hline
\end{tabular}




\begin{tabular}{|l|l|l|l|l|l|}
\hline Friend & 1.0 & 1.7 & 3.7 & 3.1 & 1.6 \\
\hline School & 4.1 & 10 & 11.1 & 6.3 & 7.4 \\
\hline Cybercafes & 32.7 & 38.3 & 51.9 & 65.6 & 42.6 \\
\hline
\end{tabular}

$\mathrm{N}=245$

Answers in percentage of respondents

Home according to these figures is the main access place for 10 percent of the surveyed population, even though 24.1 percent of the Internet users have home access. These findings are consistent with findings from interviews conducted with cybercafe managers. The managers mentioned that even people who have access at home are using cybercafes, because home use is mostly restricted to dial-up connections while cybercafes offer broadband connectivity. Furthermore, in India, using a cybercafe is much cheaper than using a dial-up connection at home which costs in the order of 40 Rupees for one hour as compared to as little as $10-15$ Rupees an hour in a cybercafe. Besides saving money while being able to use a faster connection, security reasons may also be important for people. One cybercafe manager mentioned that by using cybercafes, problems with viruses, trojans or data miners are kept away from the personal computer and there is no need to invest additional money in individual security software at home.

The table also shows that home access and access at work are more important for the upper SEC groups, with 62.2 percent of SEC A1 using home or work as their main access point, whereas cybercafes are more important for the lower SEC groups. But interestingly, even in the upper SEC group A, cybercafes are used by almost one-third of the users as their main access point. And if we look at the SEC group C, we can see that for two-thirds of this group cybercafes are the main access point.

The research from Lachmayr has shown that cybercafes in Austria have almost exclusively been used as an additional access point by people with access elsewhere, and only a marginal group has been identified as being exclusively dependent on cybercafes. The situation is quite different for India, where cybercafes are the only access point for 18.8 percent of all Internet users. The importance of cybercafes as the only access place follows the patterns indicated above. Whereas they are the only access point for just 10.2 percent of SEC group A1, almost one-third (31.3 percent) of SEC group C depends exclusively on cybercafes, with a steadily declining importance from SEC group C to SEC group A.

These findings, contrary to patterns for western countries, show that cybercafes play an important role as access points for large proportions of Indian Internet users. Almost 70 percent of the Indian Internet users frequent cybercafes, and a detailed examination showed that cybercafes are the main access point for almost half of the users (42.6 percent), with the number getting as high as almost 70 percent for SEC group $\mathrm{C}$ (middle-class).

But one has to keep in mind that cybercafes are used only by the upper-class (SEC group A1, A2) and the middle-class (SEC B, C). The lower classes (SEC D and E) have shown no Internet usage at all in this sample. The activities of this group have to be researched with more sensitive methods, in order to determine use more completely.

To obtain a closer look at the users of cybercafes, a different survey has been conducted in and in front of cybercafes in Bangalore, Mumbai and Pune. People were interviewed directly before entering or when leaving a cybercafe. Altogether, 1472 people have been interviewed with a standardized questionnaire to find out socio-economic and other background data (e.g., age, education, employment situation) and usage habits (e.g., frequency of visits, time spent at centers, services and information accessed).

\section{The users of the cybercafes}

In general, the cybercafe users are young, the average age being 26 years. More than 70 percent of the users are below 30 . The following table gives an overview on the age structure of the sample.

Table 6: Age structure of cybercafe users in India:

\begin{tabular}{|l|l|}
\hline Age group & $\begin{array}{l}\text { Percentage } \\
\text { Cybercafe Users }\end{array}$ \\
\hline 14 and below & 1.2 \\
\hline
\end{tabular}




\begin{tabular}{|l|l|}
\hline $15-19$ & 13.2 \\
\hline $20-29$ & 57.1 \\
\hline $30-39$ & 20.4 \\
\hline $40-49$ & 12.1 \\
\hline Above 50 & 3.3 \\
\hline
\end{tabular}

$\mathrm{N}=1459$

Min. 9, max. 90, avg. 26,84

The age of the surveyed users ranged between 9 and 90 years. Finding elderly people using the cybercafe (often with the help of their children or even grandchildren), gives an idea of the value this institution could have for elderly people. But at the moment, as the data show, cybercafes serve mostly the young.

Examining gender shows that cybercafes are slightly male-dominated, with 54.7 percent of users being males. But the gender divide within cybercafe users seems to be narrowing, as a survey conducted by the author in 2001 showed a ratio of 64.4 percent males against 31.6 percent women users.

\section{Employment status and education of cybercafe users}

The biggest group of users are employees ( 44.9 percent), followed by students (36.8 percent), housewives (6 percent), and the self-employed (5.5 percent); with others (unemployed, retired etc.) being 6.8 percent. Thus, students are strongly over-represented in cybercafes as compared to being only 14.4 percent of the urban population of India.

For the employed, it is interesting to examine the position and sector of work, in order to find out if cybercafes are used mainly by high-income or low-income segments of the population (see Table 7).

Table 7: Different sectors of employment

\begin{tabular}{|l|l|}
\hline Sector & Percent \\
\hline \hline Computer and software & 11.9 \\
\hline Banking and financial services & 12.3 \\
\hline Service sector & 14.6 \\
\hline Factory/Industrial worker & 3.7 \\
\hline Teachers & 13.5 \\
\hline Medical sector & 5.5 \\
\hline Shop assistant & 4.1 \\
\hline $\mathrm{N}=721$ &
\end{tabular}

Only the sectors Factory/Industrial worker and Shop assistant represent low-income jobs, and these two categories account for just 7.8 percent of the users. On the other hand, 24.2 percent of the employees work in high-income job sectors, namely software/hardware and financial services. This suggests that cybercafes are mainly used by the better off in society and confirm the findings of the street survey.

A look at education strengthens this picture: 46.2 percent of users above 25 years had a college degree and just 2.9 percent of those above 25 had only primary education or less. Interestingly, almost one percent of users were illiterate, and that this group uses cybercafes at all is notable as education is often considered a prerequisite to the use of new technologies and services. Several of the interviewed cybercafe managers confirmed that fact and pointed out that these people, as they were not in a position to make use of the Internet on their own, made use of the services with extensive help from the staff. There are several services at present like scanning, creating an email account, sending and receiving email, job search or even finding partners online, which are of available for use even by the illiterate when mediated through a human interface. But, as both surveys show, groups with low education and/or low income are only a marginal proportion of the users of cybercafes. 
After examining who comes to the cybercafe, this study took a closer look at what people come for and what they are doing in the cybercafes.

\section{What do people use?}

The most frequently used service in the cybercafe was the World Wide Web ( 90.3 percent), followed by email ( 72.3 percent), phonecalls/netphone (52.1 percent), games (49.6 percent) and chat (48.7 percent). Almost half of those interviewed also used the cybercafe for educational reasons, which may be related to the high number of students. But it should also be noted that many teachers use cybercafes in order to prepare their lessons.

In the discussion of cybercafes and the digital divide, it was mentioned that cybercafes could play an important role in offering training to people who lack the skills to use computers and the Internet. There are two mechanisms of support: informal and formal. It is much easier to measure the formal way (Is formal training offered? How important is it for revenues? How much do people use it?) than to measure informal training. Informal help may be needed constantly or just once in a while, and it can be provided by the staff or by other users, making it more difficult to define and measure.

Interestingly, just 26.4 percent of the cybercafes offered any formal training. Considered as a powerful mechanism to bridge the digital divide, training in cybercafes did not play an important role in their business strategies. Some of the cybercafe managers interviewed said they had been offering it, but the use was not as important as one would think and was very limited as a source of revenue, so it was not being offered any longer as a regular service. The relatively low importance of formal training is also shown by the user survey: Computer training has been used only by 34 percent of the people, and this number includes those who have used it just once to get started and do not need it further.

But on the other hand, informal training may be an important learning mechanism, as all cybercafe managers confirmed that help was needed by the users, in many ways and in many situations. There are plenty of users who have no idea of how to use computers, but they come to a cybercafe where the staff members create an email account or send emails for them until the users can handle these tasks themselves. These people may never have received formal training, but they are able to use the cybercafe only because of informal mechanisms of support.

\section{Reasons for using a cybercafe}

The respondents to the street survey in Bangalore were also asked their reasons for using cybercafes. One third (32.7 percent) indicated the lack of other access possibilities, which again confirms the importance of cybercafes for a significant portion of Internet users. Table 8 shows the different answers and their percentages.

Table 8: Reasons to use a Cybercafe

\begin{tabular}{|l|l|}
\hline Reason to use the Internet & $\%$ \\
\hline No other facility & 32.7 \\
\hline Cheap to use the Internet/Cheaper than at home & 26.3 \\
\hline Convenient/social place & 10 \\
\hline Learned about Internet from friends here & 9.1 \\
\hline Traveling & 7.3 \\
\hline Better speed & 5.5 \\
\hline Offers high tech & 4.5 \\
\hline Need help & 3.6 \\
\hline $\mathrm{N}=110$ & \\
\hline
\end{tabular}

The reasons cheap/cheaper than home and better speed could be seen as confirming the fact that a relatively large group of people with access at home use cybercafes. The large proportion of people who have learned from friends in cybercafes about the Internet ( 9.1 percent) is further confirmed and better seen when asking people directly where they learned about the Internet. Almost half of the Internet users (not 
cybercafe users!) had their first experience with the Internet at a cybercafe (46.5 percent), followed by work with 24.5 percent, and school with 16.5 percent. Cybercafes thus have importance for people who want to learn about the Internet.

\section{Summary: Cybercafes and the digital divide}

Taking the findings from the cybercafe survey, it appears that cybercafes according to the categories age, employment and education mostly serve the better-off groups (the young, the highly educated and the higher income groups). These findings confirm the results from the street survey, where Internet use could be measured only among the middle and upper-classes. Therefore, the theoretical assumption that cybercafes might help bridge the digital divide for the lowest SEC groups has to be rejected, at least at present.

But in the same context, it is a positive sign that currently some illiterate people are using cybercafes for a variety of reasons, without any special programs or applications for them being in place. When interviewed for this study in 2004, Mujeeb Poolakal, the general secretary of the Internet Cafe and DTP Owners Association of Kerala, confirmed this fact:

Nowadays, compared to the last two years, also illiterate people are coming for their needs. They come to collect information and mostly they want to send emails to other places or other countries. So now illiterate people are starting to come and they ask do you have this or that facility here, do $i$ get this or that information here and so on. And we are helping them and encouraging their attitude towards the Internet.

This statement also shows that illiterate people are recognized by cybercafe owners and seen as a potential target group. But as the study indicated, they use these facilities at present only to a minimal extent.

As cybercafes are presently facing a small downturn in business, it could be important for them to target new groups, especially from the lower classes. The market-driven decline in access rates in cybercafes can be seen positively as moving them into the reach of marginalised communities, but still, strategies concerning content and applications need to be developed and implemented in order to benefit these groups. Taking Gurstein's (2003) concept of effective use, the simple availability of ICT does not at all guarantee that people benefit: "The social challenge thus becomes one of ensuring that end users can do locally significant things with technology tools to which they now have access--economically, socially, and politically."

There is some locally significant content and applications available to marginalised communities in urban India at present (like online job listings, online marriage institutes, governmental document and travel services), which can benefit these groups in various ways. But although these services exist, this study shows clearly that the lower classes are not using these offerings at present. In order to reach marginalised groups in future, cybercafes need to focus on more than just providing access. To make the technology useful, they need to provide training, offer special applications and services for lower classes (e.g., email typing, document services like caste certificates). Furthermore, they need to see these users as a potential customer group.

Cybercafes in this context could learn much from successful rural Internet projects as, for example, the Information Village research project, the Akshaya project or the Drishtree project in India, where the lower classes and marginalised groups are already targeted. These rural Internet projects have all implemented interesting applications and services to attract and benefit low-income users. Learning from the experience of rural and development-oriented projects could help cybercafes target and reach out to lower income groups and expand their business to this customer base.

Whatever the impact on lower SEC groups, cybercafes have to be seen as very important institutions in urban areas of India for the middle class. This study showed that cybercafes are used by almost 70 percent of the individuals in these groups as their main access point, and that as much as one-third of the middle class is dependent on cybercafes as their only access point. Thus, cybercafes play a significantly different role in India, compared to the role they play in the most developed countries. Whereas in developed countries, they are just an additional access point for people who already have access somewhere else, they 
seem to be highly important for the middle class in India, and therefore effectively help to bridge the digital divide for this group. 


\section{References:}

Achar, A. (2001, June). ISPs turn to cyber cafés for extra revenue. Telecommunications Magazine, Retrieved April 5, 2005 from http://www.telecommagazine.com/default.asp?journalid $=2 \&$ func $=$ departments \&page $=0106 i 21 \& y$ ear $=2001 \&$ month $=6$.

Businessworld (2005). The Marketing Whitebook 2005. New Delhi, India.

Caslon Analytics (2004, September). Caslon Analytics note: Cybercafes and telecentres. Retrieved April 5, 2005 from http://www.caslon.com.au/cafenote.htm.

Compaine, B. M. (2001). The digital divide: Facing a crisis or creating a myth? Cambridge, MA: The MIT Press.

Gurstein, M. (2003). Effective use: A community informatics strategy beyond the digital divide. First Monday, 8(12). Retrieved April 5, 2005 from http://www.firstmonday.dk/issues/issue8 12/gurstein/index.html

Lachmayer, N. (2003). Digital Divide und kommerzielle Internetcafes. Vienna: 3s Research Lab.

Laegran, A. S., \& Stewart, J. (2003). Nerdy, trendy or healthy? Configuring the internet café. New Media \& Society, 5(3), 357-377.

Liff, S., \& Steward, F. (2003). Shaping e-access in the cybercafe: Networks, boundaries and heterotopian innovation. New Media \& Society, 5(3), 313-334.

Mossberger, K., Tolbert, C. J., \& Stansbury, M. (2003). Virtual inequality: Beyond the digital divide. Washington, DC: Georgetown University Press.

Norris, P. (2001). Digital divide: Civic engagement, information poverty, and the Internet worldwide. Cambridge: Cambridge University Press.

Pasricha, A. (2004, August 15). To get online, most Indians go to cybercafes. VOA News Service. Retrieved April 5, 2005 from http://apiap.blogspot.com/2004 10 _01 apiap_archive.html.

Stewart, J. (2000). Cafematics: The cybercafe and the community. In: Michael Gurstein (Ed.). Community informatics: Enabling communities with information and communication technologies (pp. 320339). Hersey, PA: Idea Group Publishing.

Vehovar, V., Batagelj, Z, \& Lozar, K. (1999). Language as a barrier. Retrieved April 5, 2005 from http://www.isoc.org/inet99/proceedings/3i/3i_3.htm.

Warschauer, M. (2003). Technology and social inclusion. Cambridge, MA: The MIT Press. 